\title{
The Implications of Civil Society in Waste Management: Case of Study Skikda, Algeria
}

\author{
Khorief Ouissem and Mahimoud Aissa
}

\begin{abstract}
This paper aims at examining the role civil societies in waste management in Skikda and evaluating their implications and results. This study provides the information needed to evaluate the rate of their participation and the ways to improve it. The data for this study were collected through a survey questionnaire conducted on the environmental associations of Skikda. The survey took into account a variety of criteria including the frequency of participation of the association, the theme(s) they focus on, the distribution of their efforts, the utilized tools, etc. The quantitative data gathered are then analyzed using Statistical Package for Social Sciences (SPSS). Finally, the results show a passive participation of associations in waste management on several levels.
\end{abstract}

Index Terms-Associations, civil society, environment, sensitization, waste management.

\section{INTRODUCTION}

In Algeria, the amount of municipal solid waste has increased substantially in the recent decades due to rapid population growth coupled with an uncontrolled urbanization [1]. Household waste and other similar wastes constitute a considerable share of the environmental pollution in Algeria [2]. The latter is an increasing problem despite the efforts made by the government, materialized in the initiation of policies and strategies as well as the creation of new institution (for example: Law No. 01-19 of 12 December 2001) [3].

Many Algerian cities, however, still experiencing many problems in waste management [1]. Skikda, the capital of Skikda province, is one of these cities. It is a coastal, touristic and industrial city situated in the East of Algeria. Skikda extends over $52 \mathrm{~km} 2$, and has a population, according to census that took place in 2016 , of 320.000 habitants with a population density of $6.153,8$ inhabitants $/ \mathrm{km}^{2}$ [4]. The quantity of solid waste in Skikda has experienced a near exponential increase in recent, as the latest statistics of Environment Direction of Skikda (DEW) demonstrate. The quantity of solid waste in 2006 was estimated to be 42.866 tons/year [5]. This number has risen by $85 \%$ (to reach 79105 tons/year) in 2013 with a daily waste generation of 0,58 $\mathrm{kg} /$ capita/day [5].

The concept of civil society is rather an ambiguous and means different things depending on the context where it is

Manuscript received May 27, 2017; revised July 23, 217

Ouissem Khorief is with the Department of Project Management, University of Constantine 3, Constantine, Algeria (e-mail: ouissamkhorief@gmail.com).

Aissa Mahimoud is with Institute of Architecture and Urbanism, University of Constantine 3, Constantine, Algeria (e-mail: mahimoud58@yahoo.fr). utilized. For instance, Alexis de Tocqueville [6] considered civil society as the birthplace and exercise of civic virtues. According to [7] the civil society is a public space between the state and citizens. This space permits the latter to engage in structured, and collective, autonomous activities of general interest. There are many forms of civil society in Algeria, being: non-governmental organisations, environmental associations, street associations, and trade unions. They all, however, share common characteristics such as independence, self-regulation, voluntary and solidarity, as well as different fundamental democratic values (freedom of opinion, freedom of assembly, etc.) [8]. The most known forms of organization of civil society are associations and the neighbourhood committees [8]. Both forms have experience a considerable increase in the last years. Currently, there are more than 108940 active associations in Algeria of which $2.03 \%$ (2505) are environmental associations and approximately $21.45 \%$ (23371) are neighbourhood committees [9]. In Skikda province, there are 2092 associations of which roughly $2.9 \%$ (59) are environmental associations and $21 \%$ (432) are neighbourhood committees.

Although environmental associations and non-governmental organisations in Algeria generally, and Skikda in particular, are becoming more and more engaged in urban and environmental services provisioning, no systematic knowledge exists on their efficiency, impact and kind of activities they provide. Additionally, in face-to-face interviews, local authorities suggested that one of the problem of the waste management strategy in Skikda is originated from the lack of participation of civil societies and their deficiency in accomplishing some parts of their role, such as educating and informing the population.

\section{Methodology}

In order to examine the implication of civil society, this study begins by identifying the major actors of solid management in Skikda and highlighting their roles. This allows pointing out and validate that civil society is the only category of actors that are responsible for the task of educating and informing the population. This, then, paves the way for an investigation about their activities, themes and the tools they utilize.

\section{A. Waste Management Actors in Skikda:}

When you submit your final version, after your paper has been accepted, prepare it in two-column format, including figures and tables.

\section{1) Public actors}

As Public actors of waste management in Skikda consist 
mainly of public institutions and enterprises, being:

- Direction of Health and Environment of the Municipality of Skikda (APC);

- Municipal Enterprise for Cleaning and Waste Management (ECONEG);

- The Public Enterprise of Landfill Management of Skikda province (EPCET);

- The direction of environment of Skikda province.

Public actors have the role of providing the necessary services, such as: the collection, transportation and processing of urban solid waste. They also design programs to protect the environment and enhance the living environment of citizen.

\section{2) Private actors}

This section consists primarily of private businesses and micro-enterprises that were created as part of the National Microcredit Management Agency (ANGEM) and the National Agency of support for youth employment (ANSEJ). Their objectives are generally the collection and the recycling of solid waste. There are many private companies in Skikda focusing on solid waste management, including : cleaning and disinfection abed Raouff company, Green cleaning and maintenance Aifa company, cleaning and disinfection Mouassi company ,etc.

\section{3) User}

The users are the principal actors in the waste management process. This category contains all types of population: inhabitants, administrators, clerks, merchants, etc.

\section{4) Civil society}

Similarly to most Algerian cities, civil society in Skikda is a category of actors that is constituted of environmental association and neighbourhood committees. This category of actor is becoming increasingly important because of the proliferation of solid waste and the inability of the municipalities and public enterprises to cope with the situation.

Due to their proximity to and direct contact with citizens, the main responsibilities of Algerian civil society in waste management are educating, informing and raising awareness of people about the environmental issues. As previously mentioned (at the end of Section 1), the local authorities stated that the population is not well informed about their tasks and responsibility of cooperating with them in waste management. Local authorities also added that they frequently do not receive a positive and practical response if they call for certain actions to be taken by the population (for example sorting the waste). Accordingly, they accused civil society actors of Skikda for failing to accomplishing their tasks of education and raising awareness. Hence, we conducted a study to analyse their implication in waste management and to examine the extent of their success/failure in fulfilling their role.

According to the National Statistics Office (NSO) [4] in Algeria, several associations are registered in the city of Skikda (cultural, social, and environmental). In the contributed study, only the environmental associations are taken into consideration. There are 7 active associations involved in the environment sector. Fig. 1 compares the number of environmental associations in Skikda city comparing the other types of associations. It can be seen that the environment is one of the less represented domains in Skikda associations.

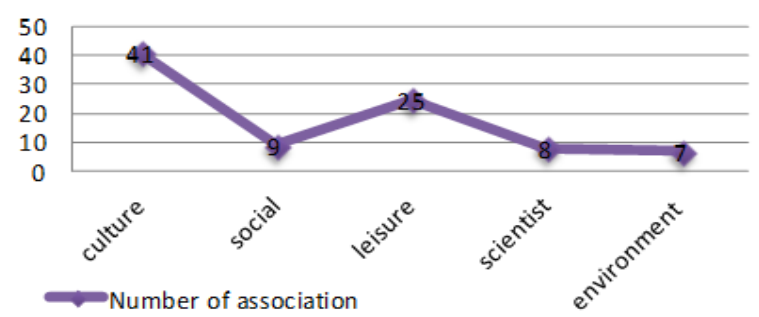

Fig. 1. Number of associations in Skikda per doman.

To assess the participation of civil society in the process of waste management, a quantitative survey was sent to the leaders of 7 associations (out of 7 environmental associations). Only 5 associations took part of the study

The survey is composed of four (4) modules:

- The profile of the association (number of volunteers, budget, name, creation date, etc.);

- Their specialized role;

- Their waste management method;

- Their actions of awareness and communication in terms of waste management taken.

The questionnaire consists of 18 questions, half of these questions are closed and the remaining half is open. The survey designated to find out about three objectives:

- The extent of participation of the considered civil society actor in the waste management process (collection, transport, recycling, and sorting);

- The nature, frequency, and media used in their actions of sensitization;

- The group targeted by their action.

\section{RESUlT AND DISCUSSION}

This section presents analyses and discusses the information of the environmental associations in Skikda gathered through the survey. Table I shows the profile of the associations that took part of the study.

According to the answers of the survey, we found that all the environmental associations considered participate in the process of waste management. The participation of some of them, however, is limited in terms of the space covered. Fig. 2 (a) illustrates that $60 \%$ of the associations are only active in some neighborhoods. One association (20\% of the total) is engaged in the municipality and another association (20\%) active in several municipalities. This suggests that more than a half of the environmental associations in Skikda have low coverage.

Fig. 2 (b) illustrates the distribution of tasks amongst the active association in the waste management process. The majority of active associations (60\%) are involved in cleaning up the beaches and $20 \%$ clean up in neighborhoods. The remaining $20 \%$ of associations are engaged in the recycling processes but not in the composting.

We found, through the survey, that all the association that took part of the study participates in the sensitization and 
raising awareness. Fig. 2 (c) depicts the method they utilize in raising awareness. Half of the associations (40\%) that are active in waste management campaign in neighborhoods and schools. One association $(20 \%)$ utilizes door to door method. Fig. 2 (d) shows their rate of actions in raising awareness. The strong majority of associations (80\%) have 1-6 missions per year and only one association stated that it has 7-12 missions per year Fig. 2 (e) indicates the themes of education and sensitization considered by the associations. $60 \%$ of the association taken into consideration said that that their sensitization subject is the sorting of solid waste and $40 \%$ target recycling themes. It can be clearly noticed the total absence of themes related to composting and waste reduction.

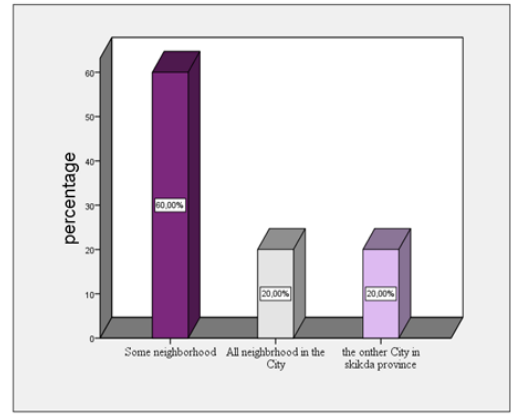

(a)

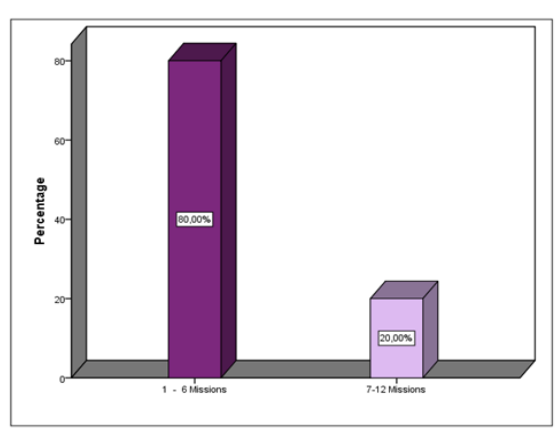

(d)

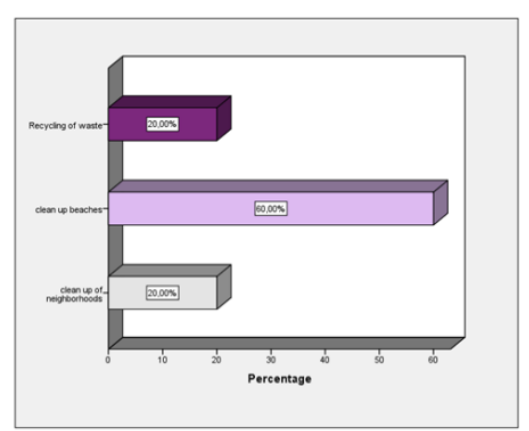

(b)

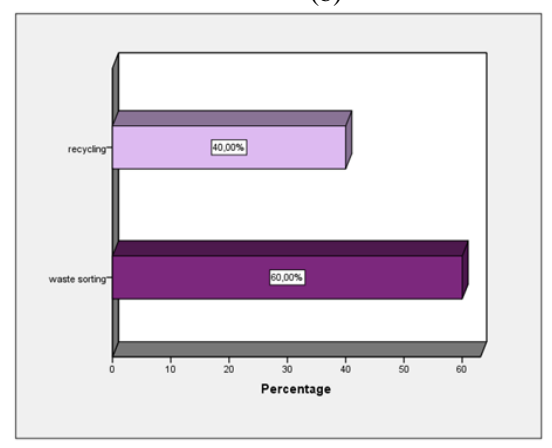

(e)

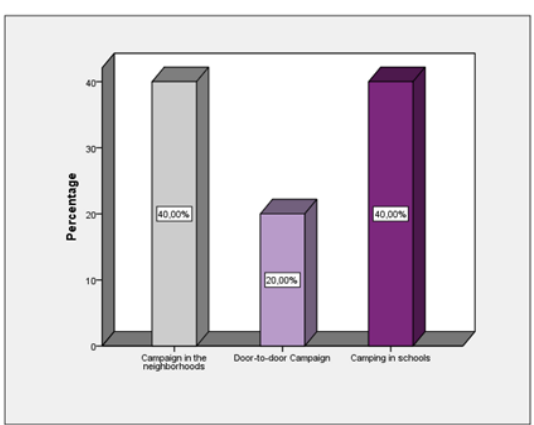

(c)

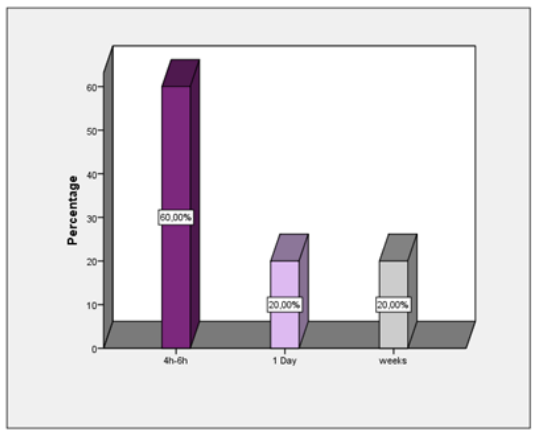

(f)

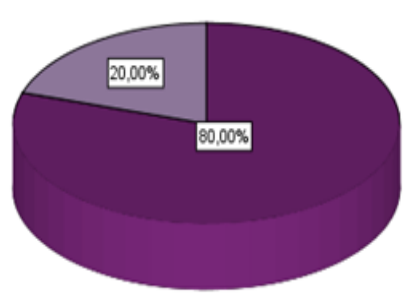

口No
口yes

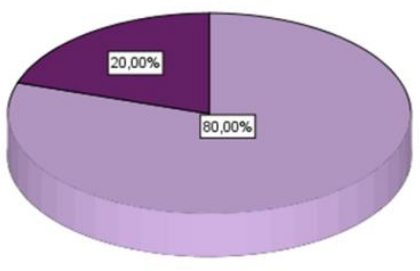

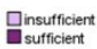

(h)

Fig. 2. The results of the survey.

TABLE I: THE PROFILE OF THE ENVIRONMENTAL ASSOCIATIONS OF SKIKDA CITY

\begin{tabular}{ccccc}
\hline \hline ASSOCIATION NAME & CREATION DATE & FIELD OF INTERVENTION & MTATUS \\
BARIQ 21 & $21 / 03 / 2006$ & ENVIRONMENT, RENEWABLE ENERGY & ACTIVE & ACTIVE \\
ECOLOGICA & - & ENVIRONMENT & 265 \\
LES ÉTOILE DE MER & $2 / 02 / 1993$ & SCIENCE, CULTURE, SPORT AND ENVIRONMENT & ACTIVE \\
SERGINA & - & SCIENCE, CULTURE, ENVIRONMENT & 250 & 220 \\
AFFAK & - & ACTIVE & ACTIVE \\
\hline
\end{tabular}

The result in Fig. 2 (f) shows the significantly low duration of the action of raising awareness by the active association considered in the study. The bar chart reveals that $60 \%$ of the association takes only between $4 \mathrm{~h}-6 \mathrm{~h}$, one association (20\%) lasts a day and another association (20\%) takes 2-3 days. A strong majority of the associations $(80 \%)$ indicated, as Fig. 2 (g) demonstrates that the duration of their action is insufficient and that they will try to improve it in the next years. Only one association (20\%) consider the duration of their action sufficient.
Fig. 2 (h) demonstrates an important aspect about civil society generally, and associations in particular, in Skikda. The majority of organizations $(80 \%)$ have never made a preliminary diagnosis to know the rate of awareness nor to evaluate and assess their performance.

The results of the survey (responses of both open and close questions) reveal that there is an insufficient participation of civil society actors in Skikda due to the

Following indicators:

- Some of the civil society actors are limited to some streets 
and location;

- They have discontinuous work rate, time limited and dependant to the official work calendar, meaning they concentrate on the international and national days of environment and local festivals of Skikda (derived from the responses of the open questions);

- Their actions of raising of awareness are superficial as they do not go in depth about some important topics of waste management (the composting for instance);

- The utilization of simple tools in raising awareness, such as flyers; and most importantly,

- No performance assessment at the end of the related actions, which considerably reduces their efficacy and the credibility of the actor.

Consequently, this study confirms the hypotheses that civil society of Skikda city are failing to accomplish their roles of raising awareness and educating citizens about their responsibility in waste management.

\section{CONClusion}

Civil societies were part of the efforts made by the Algerian government to improve the protection of the environment. They frequently have the role of compensating the inability of local governments to provide environmental services. This paper examined the implication of civil society actors in solid waste management in Skikda. It provides the information needed to assess their efficiency and impact. This paper commenced by identifying all the actors of solid waste management in Skikda and stating their roles. This allowed verifying whether the missions of civil society actors overlap with other types of actors. We found that the mission of civil society, which is mainly education and raising awareness, is independent from other actors. Then, an investigation is carried out in the form of a survey sent to all related (environmental) associations of Skikda. After gathering the data, the results showed that the civil society in Skikda is not sufficiently efficient in fulfilling their requirements.

\section{REFERENCES}

[1] B. Djemaci La gestion des déchets municipaux en Algérie: Analyse prospective et éléments d'efficacité. Université de Rouen. (2012). [Online]. Available: https://tel.archives-ouvertes.fr/tel-00804063

[2] S, Kouloughli and S. Kanfoud, "Municipal solid waste management in constantine, Algeria," J Geosci Environ Prot. 2017, vol. 5, no. 1, p. 85.

[3] JORF N ${ }^{\circ} 77$, "Law N 01-19 on the management, control and disposal of waste," 2001.

[4] ONS. (2016). Office National of Statistics. [Online]. Available: http://www.ons.dz/-Demographie-.html

[5] DEW, "The direction of environment of Skikda province," 2015.

[6] A. Alexis de Tocqueville, University of California Press, 1985.

[7] G. White, "Civil society, democratization and development (I) Clearing the analytical ground," Democratization, 1994, pp. 375-90.

[8] JORF $\mathrm{N}^{\circ} 02$, Law 12/06 of 12 relating to associations, 2012.

[9] MICL, Ministry of the Interior and Local Government, 2017.

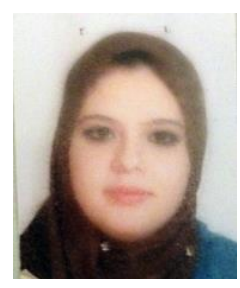

Khorief Ouissem was born in El Harrouch city Skikda, Algeria, on the $21^{\text {st }}$ of October 1990. In 2013 she obtained her masters degree in project management from University of Constantine 3. In 2015, she started working as Assistant Teacher at the same university. She is a member of AVFM laboratory in the department of architecture. Her $\mathrm{PhD}$ research topic is about Waste Management.

Mahimoud Aissa is a senior lecturer in the Department of Architecture in the University of Constantine 3. In 2009, he became the head of the department of architecture. In 2014, he became the vice dean of the same university. Dr. Mahimoud teaches research methodology. His $\mathrm{PhD}$ and research is about ecology, heritage and sustainability. 